\section{FRI0578 LACC1 MUTATION IN THREE SIBLINGS WITH POLYARTHRITIS WITHOUT SYSTEMIC MANIFESTATIONS}

Ankita Singh ${ }^{1}$, Deepti Suri ${ }^{2}$, Prince Jacob ${ }^{3}$, Katta Mohan Girisha ${ }^{3}$, Ankur Jindal ${ }^{4}$, Surjit Singh ${ }^{4} .{ }^{1}$ Post Graduate Institute of Medical Education and Research, Chandigarh, Pediatrics, Allergy Immunology Unit, Chandigarh, India; ${ }^{2}$ Post Graduate Institute of Medical Education and Research, Chandigarh, Advanced Pediatrics Centre, Chandigarh, India; ${ }^{3}$ Kasturba Medical College, Manipal, Medical Genetics, Manipal, India; ${ }^{4}$ Post Graduate Institute of Medical Education and Research, Chandigarh, Advanced Pediatrics Centre, Allergy Immunology Unit, Chandigarh, India

Background: Juvenile idiopathic arthritis (JIA) is a complex group of disorders characterized by wide phenotypic diversity and genetic heterogeneity. It has multifactorial etiology varying among different subtypes. There are emerging reports on new gene loci being identified especially in families with many affected members $(1,2)$

Objectives: To report 3 siblings with polyarthritis who were detected to have mutation in Laccase domain containing 1 (LACC 1) gene.

Methods: We reviewed case records of 3 siblings with infantile onset polyarthritis and performed whole exome sequencing on their DNA samples for $L A C C 1, M M P 2$ and WISP genes.

Results: A non-consanguineous family from north-western part of India reported with 3 daughters having polyarticular joint disease. The chronology of symptoms was similar in all 3 children. Joint symptoms started in later half of infancy with swelling of knee and ankle. This disease was progressive and over the following 2 years there was involvement of small joints and cervical spine too (Figure 1) along with deformities and contractures. The investigations at the time of first evaluation are given in Table 1. Radiographs in all 3 sisters showed osteoporosis and erosion of vertebrae (Figure 2).

The children were initially started on naproxen. Later, in view of rheumatoid factor positivity in eldest sister we decided to give them a trial of oral prednisolone (initially $1 \mathrm{mg} / \mathrm{kg}$ and subsequently tapered) and subcutaneous methotrexate $\left(10 \mathrm{mg} / \mathrm{m}^{2} /\right.$ week $)$. Methotrexate was continued on long term basis. Over the next 24 months of follow-up the clinical improvement has been sustained.

Whole-exome-sequencing in all three girls has revealed mutation in LACC1 gene [Exon 4; c.832G>C; p.(Ala278Pro), Homozygous, Autosomal recessive].

Conclusion: This case report further provides evidence to the emerging association of LACC1 mutation with familial aggregation of $\operatorname{JIA}(1,2)$. Long term follow-up of these patients is necessary to determine the natural course of this intriguing clinical entity.

\section{REFERENCES:}

[1] Wakil SM, Monies DM, Abouelhoda M, Al-Tassan N, Al-Dusery H, Naim EA, et al. Association of a Mutation in LACC1 With a Monogenic Form of Systemic Juvenile Idiopathic Arthritis: Monogenic Systemic Juvenile Idiopathic Arthritis. Arthritis \& Rheumatology. 2015 Jan;67(1):288-95.

[2] Karacan I, Uğurlu S, Şahin S, Everest E, Kasapçopur Ö, Tolun A, et al. LACC1 Gene Defects in Familial Form of Juvenile Arthritis. J Rheumatol. 2018 May;45(5):726-8.

Disclosure of Interests: None declared

DOI: 10.1136/annrheumdis-2019-eular.6587

\section{FRI0579 \\ PREDNISONE VERSUS STANDARD THERAPY IN SYDENHAM'S CHOREA: RESULTS FROM A RETROSPECTIVE STUDY}

Elena Favaretto ${ }^{1}$, Giulia Gortani ${ }^{2}$, Gabriele Simonini ${ }^{3}$, Serena Pastore ${ }^{2}$, Rolando Cimaz ${ }^{3}$, Alberto Tommasini ${ }^{2}$, Andrea Taddio ${ }^{1,2}$. ${ }^{1}$ University of Trieste, Trieste, Italy; ${ }^{2}$ Institute of Maternal and Child Health, IRCCS Burlo Garofolo, Trieste, Italy, ${ }^{3}$ Meyer Children's Hospital, Florence, Italy

Background: Sydenham's chorea is a major and delayed manifestation of acute rheumatic fever [1] and is considered to be a prototype of an autoimmune disorder triggered by an infectious agent. Aside from conventional symptomatic treatment (carbamazepine, valproate, neuroleptics), the use of steroids has also been advocated, mainly in severe, drug-resistant cases or if clinically disabling side effects develop with first line therapies. However the evidence of corticosteroids efficacy is weak.

Objectives: To describe the efficacy of corticosteroids therapy versus standard therapy in children affected by Sydenham's Chorea in a cohort of Italian patients with acute rheumatic fever (ARF).
Methods: A retrospective observational study was conducted. The hospital records for all children diagnosed as having ARF between January 2007 and December 2017 in the Pediatric Rheumatology Division of the Meyer Children Hospital (Florence) and IRCCS Burlo Garofolo (Trieste) were reviewed. The diagnosis of ARF was made by pediatric rheumatologists and all the children discharged with a ICD 9 code consistent with ARF were included. For the purpose of the study only patients with Sydenham's Chorea were enrolled. Files were analyzed for demographic data, clinical and laboratory findings on admission and during the hospital stay and patients with incomplete information were excluded. Time and resolution of choreic symptoms were evaluated in consideration of presence or absence of corticosteroid therapy.

Results: Thirty patients were enrolled; 23 out of $30(76 \%)$ had generalized chorea. $15(50 \%)$ were treated with prednisone $(2 \mathrm{mg} / \mathrm{kg} / \mathrm{day}$ in a single administration per day for 14 days before tapering), 11 (36.6\%) were not treated with medications and 4 (13.3\%) received pimozide or sodium valproate. We considered together patients who did not receive any specific therapy for chorea and patients who received only symptomatic anti-chorea drugs (pimozide in 3 cases and sodium valproate in 1 case). Therefore we obtained two groups of 15 participants each: "Prednisone group" and "Standard therapy group". The time required for clinical improvement in the two groups appeared statistically different $(P=$ 0.002). In "Prednisone group" the median time for improvement was 4.0 days (interquartile range: 3) whereas in "Standard therapy group" it was 16.0 days (interquartile range: 16). Furthermore, the "Prednisone group" had a median remission time of 30.0 days (interquartile range: 34 ) whereas "Standard therapy group" presented a median remission time of 135.0 days (interquartile range: 309$)(P<0.001)$. At least one episode of relapse occurred in $1(6.7 \%)$ out of 15 patients in the "Prednisone group" and in 3 patients $(20 \%)$ in the "Standard therapy group". However, the difference is not statistically significant ( $p=0.598)$.

Conclusion: Our study shows that corticosteroid therapy is associated with a faster resolution of Sydenham's Chorea's symptoms compared to treatments considered of first line, such as: no therapy, valproate or pimozide.

Disclosure of Interests: Elena Favaretto: None declared, Giulia Gortani: None declared, Gabriele Simonini Grant/research support from: Abbvie Speakers bureau: Abbvie, Serena Pastore: None declared, Rolando Cimaz: None declared, Alberto Tommasini: None declared, Andrea Taddio: None declared

DOI: 10.1136/annrheumdis-2019-eular.8181

\begin{tabular}{|l|l|}
\hline FRI0580 & ULTRASONOGRAPHY SCORE CORRELATES WITH \\
DISEASE ACTIVITY IN JUVENILE IDIOPATHIC \\
ARTHRITIS - ENTHESITIS RELATED ARTHRITIS - A \\
CROSS SECTIONAL OBSERVATIONAL STUDY FROM \\
INDIA
\end{tabular}

harikrishnan velayudhan pillai, Rasmi Ranjan Sahoo, Saumya Ranjan Tripathy, Urmila Dhakad, Puneet Kumar, Anupam Wakhlu, Siddharth Kumar Das. King George's Medical University, Rheumatology, Lucknow, India

Background: Enthesitis is a distinct clinical hallmark of spondyloarthropathy in children and adults. Ultrasonography (US) is a powerful tool to detect enthesitis. There are only a few studies on US detected enthesitis in Juvenile Idiopathic Arthritis - Enthesitis Related Arthritis (JIA-ERA) from India.

Objectives: To assess the presence of clinical and US detected enthesitis in JIA- ERA and to correlate with disease activity.

Methods: 51 consecutive JIA-ERA patients fulfilling the ILAR classification criteria were evaluated clinically and sonographically from October 2016 to September 2017 in a tertiary care centre from Northern India. Enthesitis was clinically assessed using the MASES (Maastricht Ankylosing Spondylitis Enthesitis Score). Additionally peripheral entheseal sites of lower limb (insertion of plantar fascia at calcaneal tuberosity, insertion of Achilles at superior pole of calcaneus, quadriceps tendon at superior pole of patella and patellar tendons proximally at inferior pole of patella and distally at anterior tibial tuberosity) were clinically and sonographically assessed for enthesitis. The clinical assessment included JADAS 27 and BASDAI for disease activity and BASFI for function. Ultrasound was performed with a multi-frequency linear-array transducer $(8-13 \mathrm{MHz})$ using $\mathrm{B}$ mode settings of dynamic range (40-50dB); GS- frequency $(11-13 \mathrm{MHz})$; GS gain $(60 \mathrm{~dB})$. Power Doppler (PD) mode settings used: pulsed repetition frequency $(400-800 \mathrm{~Hz}$ ); PD-gain (highest possible gain with minimum background noise). US parameters (hypo echogenicity, increased thickness of entheses, intratendinous calcification, enthesophyte and erosion(s)) were assessed according to OMERACT 2014 definitions of ultrasonography 
findings of enthesitis (1). Each parameter at every site was scored as 1 if present and 0 if absent. Grading of Power Doppler signals was done as per definition by Kiris et al (2); Grade 0-no signal, Grade 1- separate dot signals or short linear signals, Grade 2- vascularity involving less than half of the enthesis, Grade 3-vascularity involving more than half of the enthesis. US enthesitis score was calculated by adding 1 point for each positive finding and the grade of PD. PD score was calculated by adding the grade of PD. Presence of clinical and US detected enthesitis was correlated with parameters of disease activity by Spearman's correlation coefficient.

Results: The mean age of patients was $14.3 \pm 3.2$ years with mean duration of disease $34.6 \pm 4.9$ months. Male: Female ratio was $7.5: 1$. Clinical enthesitis was seen in 36 of the 51 patients $(70.5 \%)$ while US detected enthesitis in all $(p<0.0001)$. The mean JADAS score, BASDAI and BASFI were $17.1 \pm 10.2,4.1 \pm 2.4$ and $37.2 \pm 27.2$ respectively, indicating active disease. The US enthesitis score correlated positively with JADAS $(r=0.3$, $P=0.03)$, BASDAI $(r=0.39, P=0.005)$ and BASFI $(r=0.38, P=0.006)$. PD score correlated positively with BASFI $(r=0.33, P-0.02)$, but did not correlate with JADAS $(r=0.22, P=0.1)$, BASDAI $(r=0.24, P=0.08)$.

Conclusion: Ultrasound is more sensitive in detecting enthesitis in JIAERA than clinical assessment. The US enthesitis score correlated positively with disease activity which has implications for treatment.

\section{REFERENCES:}

[1] Terslev L, Naredo E, lagnocco A, Balint PV, Wakefield RJ, Aegerter P, et al. Defining enthesitis in spondyloarthritis by ultrasound: results of a Delphi process and of a reliability reading exercise. Arthritis Care Res (Hoboken). May;66(5):741-8

[2] Kiris A, Kaya A, Ozgocmen S, Kocakoc E. Assessment of enthesitis in ankylosing spondylitis by power Doppler ultrasonography. Skeletal Radiol. 2006 Jul;35(7):522-8.

Disclosure of Interests: None declared

DOI: 10.1136/annrheumdis-2019-eular.2884

\section{FRI0581 COMPARISON OF CLINICAL CHARACTERISTIC IN ADULTS AND CHILDREN WITH GOUT}

Shaoling Zheng ${ }^{1}$, Pui.Y Lee ${ }^{2}$, Shuyang Chen"1, Yukai Huang ${ }^{1}$, LI Tian-Wang ${ }^{1}$. ${ }^{1}$ Guangdong Second provincial General Hospital, Department of Rheumatology and Immunology, Guangzhou, China; ${ }^{2}$ Boston Children's Hospital, Division of Allergy, Immunology and Rheumatology, Boston, United States of America

Background: The incidence of gout in China is increasing in adults as well as children. The clinical manifestations of juvenile gout are not well described due to the limited number of cases in the past. Delineating the features of adult and juvenile gout may help pediatric providers recognize gout more effectively.

Objectives: We aim to describe and compare the clinical characteristic of adults and children with gout.

Methods: A total of 51 juvenile gout patients (age $\leq 18$ years) and 337 adult gout patients in our hospital from Jan 2016 to Dec 2018 were enrolled in the study. Clinical parameters and laboratory data of the 2 groups were analyzed.

Results: The average age of onset in children with gout was $15.0 \pm 1.9$ years and the youngest patient was 8 years old. Compared to the adult group, juvenile gout patients displayed lower BMI (23.0 \pm 3.8 vs. $25.6 \pm 3.5$ $\left.\mathrm{kg} / \mathrm{m}^{2}, \quad P<0.001\right)$ but higher serum uric acid levels $(9.98 \pm 2.65$ vs. 8.09 $\pm 2.47 \mathrm{mg} / \mathrm{dL}, \quad P<0.001)$. Interestingly, systemic inflammation was less prominent in children compared to adult as illustrated by lower C-reactive protein levels $(7.1 \pm 13.5$ vs. $23.7 \pm 40.7 \mathrm{mg} / \mathrm{L}, P=0.004)$ and lower erythrocyte sedimentation rate $(12.7 \pm 12.9$ vs. $33.1 \pm 34.2 \mathrm{~mm} / \mathrm{hr}, P<0.001)$. Renal function impairment was rare in children compared to adults (serum creatinine $98.73 \pm 19.04$ vs $120.38 \pm 34.58 \mu \mathrm{mol} / \mathrm{L}, P<0.001$ ). In terms joint manifestations, juvenile gout was associated with greater finger joint involvement $(23.53 \%$ vs. $6.82 \%, \quad P<0.001)$ and less knee involvement (11.76\% vs. $41.84 \%, \quad P<0.001)$ compared to adults. Ankle involvement was slightly more common in the pediatric group $(49.02 \%$ vs. $30.56 \%$ in adults, $P=0.009)$ while MTP was similarly affected $(50.98 \%$ vs. $32.94 \%$, $P=0.012)$. In addition, tophi was found in four cases $(7.8 \%)$ in the juvenile group compared to 113 cases in adults $(33.5 \%)$, suggesting that although less common, advanced features of gout can also occur in children.

Conclusion: Juvenile gout is associated with higher serum uric acid levels and greater involvement of finger joints. Correlations with BMI and systemic inflammation were less prominent compared to gout in adults. These findings will help clinicians better recognize gout in children.

\section{REFERENCES:}

[1] Chen, S.Y. and M.L. Shen, Juvenile gout in Taiwan associated with family history and overweight. J Rheumatol, 2007. 34(11): p. 2308-11.

[2] Lu, C.C., et al., Clinical characteristics of and relationship between metabolic components and renal function among patients with early-onset juvenile tophaceous gout. J Rheumatol, 2014. 41(9): p. 1878-83.

Disclosure of Interests: None declared

DOI: 10.1136/annrheumdis-2019-eular.5463

\section{Other orphan diseases}

\section{FRI0582 NON-INFECTIOUS UVEITIS AS A MANIFESTATION OF THE IMMUNE RECONSTITUTION INFLAMMATORY SYNDROMEIN PATIENTS INFECTED BY HIV}

Ester Carreño, Andrea Maria Alvear Torres, Nelida Muñoz, Francisco Javier de la Hera Fernandez, Sheila Recuero Diaz, Fredeswinda Romero, Olga Sanchez Pernaute. Hospital Universitario Fundación Jiménez Díaz, Madrid, Spain

Background: Immune reconstitution inflammatory syndrome (IRIS) is a paradoxical clinical worsening of an already known condition or the new onset of an inflammatory manifestation that is presumably related with the immune reconstitution after starting highly active anti-retroviral therapy (HAART) in patients infected by the human immunodeficiency virus (HIV). Objectives: The aim of this study is to describe the clinical characteristics, presentation and response to immunosuppressive treatment in patients with uveitis secondary to ocular IRIS in our cohort of patients infected by HIV.

Methods: Retrospective review of clinical charts of patients diagnosed with HIV and non-infectious uveitis. Data collected included: demo graphics, anatomic classification of the uveitis, phenotypic diagnosis of the uveitis, other systemic immune-mediated disorders (IMD), time from HIV diagnosis to uveitis, CD4 count, viral load, treatment and complications of treatment and time of follow-up.

Results: Nine-teen patients (17 males) were included in the study. The mean age at the time of HIV diagnosis was $35.4 \pm 9.6$ years. The time lag between HIV diagnosis and the onset of uveitis was $9 \pm 8.9$ years. Mean CD4 count was $649 \pm 292 \mathrm{cells} / \mathrm{ml}$, while the viral load was undetectable in 13 out of 17 cases. In 2 patients, there were a worsening of a previous IMD and in 6 patients another IMD was diagnosed prior to or concurring with the uveitis diagnosis ( 3 cases of reactive arthritis). The most common anatomic classification of the uveitis was anterior (13 cases). The use of immunosuppressive therapies to control either the ocular syndrome or the additional IMD was necessary in 6 patients (including biologics in 4 cases) during the follow-up. Only one patient had a complication of the immunosuppressive treatment. The mean follow-up was 43.8 months (range: 0.6 -115.7).

Conclusion: Non-infectious uveitis could be the first manifestation of immune-mediated systemic disease in patients with well-controlled HIV infection. Immunosuppression appeared to be a safe therapeutic option in our cohort of patients.

\section{REFERENCES:}

[1] Shelburne SA, 3rd, Hamill RJ, Rodriguez-Barradas MC, et al. Immune reconstitution inflammatory syndrome: emergence of a unique syndrome during highly active antiretroviral therapy. Medicine (Baltimore) 2002;81 (3):213-27. [published Online First: 2002/05/09]

[2] Murdoch DM, Venter WD, Van Rie A, et al. Immune reconstitution inflam matory syndrome (IRIS): review of common infectious manifestations and treatment options. AIDS Res Ther 2007;4:9. Doi: 10.1186/1742-6405-4-9 [published Online First: 2007/05/10]

[3] Vega LE, Espinoza LR. HIV infection and its effects on the development of autoimmune disorders. Pharmacol Res 2018;129:1-9. Doi: 10.1016/j. phrs.2018.01.005 [published Online First: 2018/01/15]

[4] Sokoya T, Steel HC, Nieuwoudt M, et al. HIV as a Cause of Immune Activation and Immunosenescence. Mediators Inflamm 2017;2017:6825493. Doi: 10.1155/2017/6825493 [published Online First: 2017/12/07]

[5] Yeo TH, Yeo TK, Wong EP, et al. Immune recovery uveitis in HIV patients with cytomegalovirus retinitis in the era of HAART therapy-a 5-year study from Singapore. J Ophthalmic Inflamm Infect 2016;6(1):41. Doi: 10.1186/ s12348-016-0110-3 [published Online First: 2016/11/09]

Disclosure of Interests: Ester Carreño Speakers bureau: Abbvie and Allergan, Andrea Maria Alvear Torres: None declared, Nelida Muñoz: None declared, Francisco Javier de la Hera Fernandez: None declared, SHEILA 